\title{
Pharmacological Options in Atherosclerosis: A Review of the Existing Evidence
}

Keshav Kumar Gupta · Shair Ali · Ranjodh Singh Sanghera

Received: October 16, 2018 / Published online: December 12, 2018

(C) The Author(s) 2018

\begin{abstract}
Coronary heart disease (CHD) is the leading cause of mortality worldwide and high lowdensity lipoprotein (LDL) cholesterol levels have been shown to be key in the pathogenesis of this condition. Lipid control has therefore been the subject of decades of research and has led to many large and robust randomized controlled trials, as well as the highest grossing drug of all time-Lipitor (atorvastatin). Statin therapy has long been indicated for secondary and more recently primary prevention. However, despite the large-scale use of statins, CHD prevalence remains high, and some patients do not respond to statin therapy. There has been a large push to find and test alternative lipidlowering agents, these include fibrates, cholesterol absorption inhibitors, and proprotein convertase subtilisin/kexin type 9 (PCSK-9)
\end{abstract}

Enhanced digital features To view enhanced digital features for this article go to https://doi.org/10.6084/ m9.figshare.7371020.

K. K. Gupta ( $\square)$

Sandwell and West Birmingham Hospitals NHS

Trust, Birmingham, UK

e-mail: keshav.gupta@nhs.net

S. Ali

St George's Hospital NHS Trust, London, UK

R. S. Sanghera

Department of Public Health, Sandwell and West

Birmingham NHS Trust, Birmingham, UK inhibitors. It is the aim of this review to assess the literature surrounding each of these groups of drugs.

Keywords: Cholesterol absorption inhibitor; Fibrates; Lipid; LDL; PCSK-9 inhibitor; Statin

\section{INTRODUCTION}

Atherosclerosis is a chronic inflammatory process that leads to arterial lumen narrowing $[1,2]$. Its pathophysiology is complex (Fig. 1), involving endothelial dysfunction, intimal thickening, and atheromatous plaque formation [3]. Plaque rupture forming a thrombus, or continued plaque growth leading to stenosis, can both occlude arteries leading to ischemia and infarction [4-7]. Heart disease (including coronary heart disease, hypertension, and stroke) remains the number one cause of death in the US. Coronary heart disease is the leading cause $(43.8 \%)$ of deaths attributable to cardiovascular disease in the US, followed by stroke $(16.8 \%)$, heart failure $(9.0 \%)$, high blood pressure $(9.4 \%)$, diseases of the arteries $(3.1 \%)$, and other cardiovascular diseases (17.9\%) [8].

Elevated low-density lipoprotein cholesterol (LDL-C) is a major risk factor for CHD [9]. This is because of its crucial role in the promotion, development, and progression of atherosclerosis [10]. Clinical evidence has shown a 10\% 


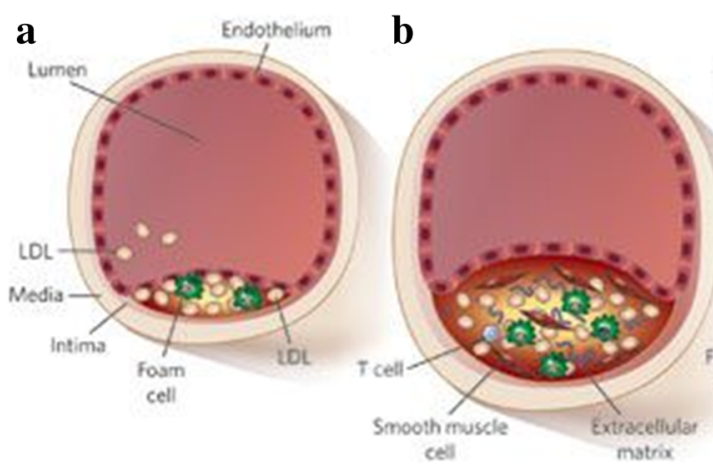

Fig. 1 a Atherogenic lipoproteins such as low-density lipoproteins (LDLs) entering the intima are modified, by oxidation or enzymatic activity, and aggregate within the extracellular intimal space. Unregulated uptake of these lipoproteins by macrophages generates foam cells and fatty streaks. These are usually asymptomatic. b Vascular smooth muscle cells secrete large amounts of extracellular-matrix components, such as collagen, which increase the retention and aggregation of atherogenic lipoproteins. The inflammatory state is potentiated by monocyte and leukocyte recruitment. As the plaque grows, compensatory remodeling (adaptive intimal thickening) occurs to

increase in LDL-C to increase CHD risk by $20 \%$ [11]. A large multi-center trial [12] in 52 countries found that dyslipidemia accounted for nearly $50 \%$ of risk for developing myocardial infarction (MI). Furthermore, the Cholesterol Treatment Trialists' (CTT) Collaboration confirmed that lowering LDL-C reduces cardiovascular disease (CVD) in a dose-dependent relationship [13].

Therefore, multiple guidelines [14-16] identify lipid management targets, specifically LDL$\mathrm{C}$, as the focus for reducing cardiovascular risk [17]. Patients with a higher cardiovascular (CV) risk require greater reductions in their LDL-C or lower absolute LDL-C targets compared to those with a lower overall CV risk [14]. Additionally, a recent review [10] found that nine guidelines out of 12 recognized LDL-C as the primary target for reducing CHD risk.

This review will evaluate the current evidence for the treatment options in atherosclerosis by comparing statins with other lipidlowering drugs. These are fibrates, cholesterol absorption inhibitors, and proprotein convertase subtilisin/kexin type 9 (PCSK-9) inhibitors.

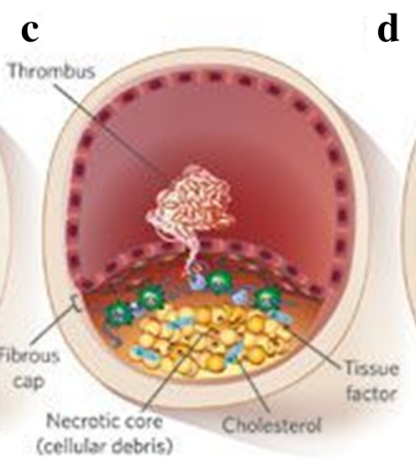

d

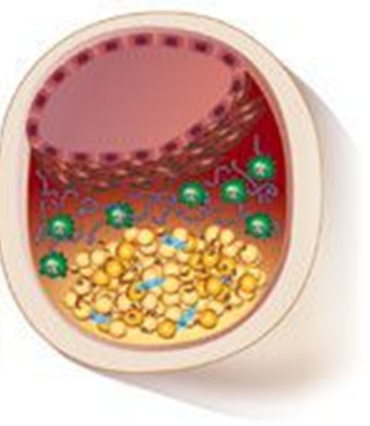

preserve the lumen diameter. c Foam cells eventually die and release cellular debris, which forms a necrotic core. Smooth muscle cells form a fibrous cap beneath the endothelium, which walls off the plaque from the blood. d The advanced lesion can either rupture or continue to grow, eventually leading to clinically significant obstructive disease. Reproduced by permission from Springer Nature, Nature, Translating molecular discoveries into new therapies for atherosclerosis, Daniel J. Radar \& Alan Daugherty (2008, Vol 451, 904-913)

This article is based on previously conducted studies and does not contain any studies with human participants or animals performed by any of the authors.

\section{STATINS}

Currently, statins are the first-line treatment in primary and secondary prevention of cardiovascular disease [18]. They work by inhibiting the rate-limiting enzyme in cholesterol biosynthesis-3-hydroxy-3-methylglutaryl coenzyme A (HMG-CoA) reductase [19]. The body responds to this by upregulating the hepatocyte LDL receptors (LDL-R). This increases hepatic uptake of LDL-C from the circulation [19].

\section{Secondary Prevention}

Many clinical trials have been conducted to show the efficacy of statins in different patient CHD risk groups. For example, the $4 \mathrm{~S}$ group [20] randomized 4444 high-risk patients (i.e., with a history of CHD and elevated LDL-C) into an 
intervention or placebo group. Over 5.4 years, the statin group had lower total cholesterol and LDL-C levels. Long-term simvastatin therapy was concluded to reduce coronary mortality and major coronary events in high-risk CHD patients. The advantages of this study are the large sample size, long-term follow-up (importantly with no loss-to follow up), and the clinically relevant primary end point. However, the low percentage $(19 \%)$ of women enrolled makes a positive conclusion hard to extrapolate to the female sub-group.

Other studies examined statin effects in lower-risk groups. The LIPID trial [21] demonstrated pravastatin to reduce CHD mortality, allcause mortality, and cardiovascular events in patients with broad baseline cholesterol levels (Fig. 2). The CARE trial [22] showed the efficacy of statins in reducing coronary events and stroke in patients with average cholesterol levels. However, the trial was based in the USA and Canada and underrepresented ethnic groups. Therefore, caution must be applied when generalizing conclusions to other populations, as other factors such as diet and ethnicity are known to be confounders for CHD [23].

Sub-group analysis from both trials [24, 25] demonstrated that statins reduce the frequency of cardiovascular events in diabetics and nondiabetics with impaired fasting glucose. The LIPID analysis also showed a reduction in absolute risk of stroke [24]. It is likely, however, that in both studies, the incidence of other comorbidities, such as obesity and hypertension, was higher in the diabetic group than the placebo. These are known risk factors for CHD [26], which are hard to control. Better steps could be taken to match these baseline characteristics in both groups, as was done in the $4 \mathrm{~S}$ trial [20].

The Heart Protection studies (HPS) [27, 28] backed up these results. Simvastatin significantly reduced rates of MI, stroke, and revascularization in high-risk and diabetic groups irrespective of their initial cholesterol levels. The size of the benefit was dependent on their overall risk of major vascular events rather than their blood lipid concentrations. They therefore advocated for statin use to be considered for patients at risk of any vascular, not just cardiovascular, events. The US Food and Drug Administration (FDA) changed simvastatin indications to those at high-risk of vascular events rather than just for those with high cholesterol following this publication [29].

\section{Primary Prevention}

Statin efficacy was taken a step further and shown to be beneficial even in primary prevention. The WOSCOP [30] found that pravastatin reduced the relative risk of coronary events, and deaths from all cardiovascular causes in addition to lowering LDL-C by $26 \%$. The study was robust in the sense that sub-group analysis demonstrated the effect to be independent of age, smoking status, and other vascular risk factors. An important study limitation, however, is the inclusion of only males with severe hypercholesterolemia.

More recently, a 20-year WOSCOPS followup [31] showed that 5-year statin treatment reduced cardiovascular disease outcomes over two decades. This observation may be due to the relatively young age of patients receiving the initial treatment (mean age, 55 years). Nevertheless, the results show a clear benefit with statins throughout the "lifetime period for risk of cardiovascular morbidity and mortality", and therefore show their advantage in primary prevention.

The AFCAP study [32] analyzed statin use in primary prevention in patients with average cholesterol levels. It concluded that lovastatin "reduces the risk for the first major coronary event in men and women". However, there was a lack of explanation on their method of randomization, which is concerning considering such a large sample size. These results were reproduced by a 2008 meta-analysis [33] and a 2013 systematic review [34]. Another metaanalysis specifically assessing primary prevention in the elderly also found a reduction in vascular events but no significant effect on allcause or cardiovascular mortality [35]. However, in addition to vascular event benefits, an 11-year follow-up of the ASCOT-LLA trial $[36,37]$ showed a reduction in all-cause mortality. 

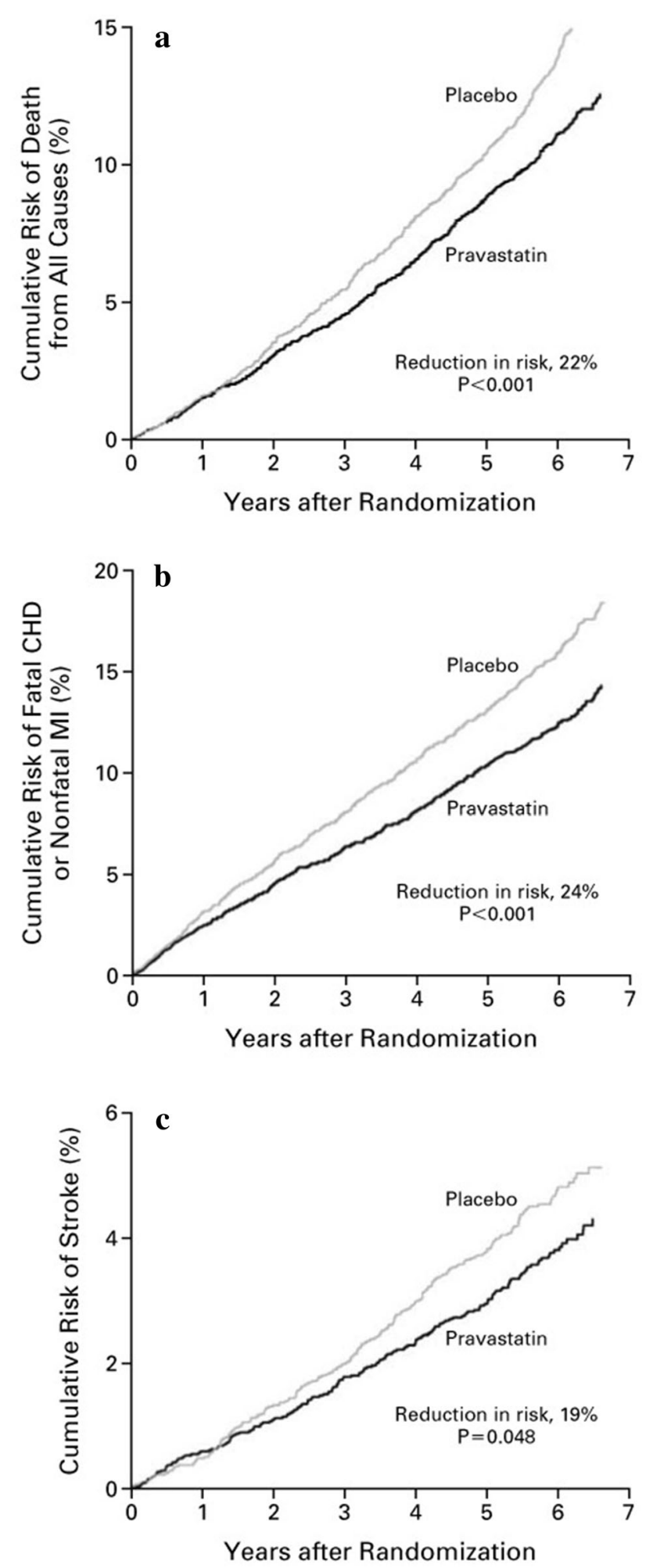
4Fig. 2 Kaplan-Meier estimates of the incidence of major secondary outcomes in the pravastatin and placebo groups. a Mortality from all causes. b Death due to coronary heart disease (CHD) or nonfatal myocardial infarction (MI). c Stroke of any type. The graphs show a reduction in risk in the pravastatin group for all-cause mortality, cardiovascular events, and stroke. For every 1000 patients in the pravastatin group, the analysis showed that death from any cause was avoided in 30 patients, death due to CHD or nonfatal MI in 35 patients, and stroke in eight patients. Reproduced by permission from Elsevier, NEJM, Prevention of Cardiovascular Events and Death with Pravastatin in Patients with Coronary Heart Disease and a Broad Range of Initial Cholesterol Levels. The Long-Term Intervention with Pravastatin in Ischaemic Disease (LIPID) Study Group 1998;Vol 339(19):1349-1357

\section{Adverse Effects}

As with all drugs, statins are not free from adverse effects (AEs). In 2013, 17\% of 100,000 patients taking statins reported AEs and 10\% discontinued therapy [38]. However, the study used secondary retrospective data, which may have resulted in misinterpretation and incomplete documentation. When patients who discontinued were rechallenged, it was found that many $(92.2 \%)$ could eventually tolerate statins long-term. This was supported by a meta-analysis, which found AEs to be 'uncommon', and discontinuation rates to be no higher than placebo [39]. One possible explanation for the discrepancy in AEs reported in RCTs and realworld observations is that RCTs use a run-in period, which excludes those who are intolerant to statins from the randomization process, thereby artificially decreasing the $\mathrm{AE}$ rate. However, a meta-analysis comparing trials with and without a run-in phase found a similar adherence rate discrediting this theory [40]. This pattern of conflicting evidence is preserved throughout trials monitoring statin AEs, making it difficult to establish their true risk.

Myopathies are the most common reported AE [41], ranging from myalgia to rhabdomyolysis. Again, the reported incidence of myalgia is variable, ranging from 1 to 20\% [42-44]. The FDA [45] cautioned against high simvastatin doses in 2012 due to large studies reporting increased myopathy risks [46].

Previous epidemiological studies have suggested lowering total cholesterol levels and cancer are correlated. Studies have detected an increased risk of specific cancers in specific populations such as the elderly $[47,48]$ or in

Table 1 Summary of the effects of statins on LDL-C and vascular events and mortality Modified by permission from Elsevier: American Journal of Cardiology. Review of Primary and Secondary Prevention Trials with Lovastatin, Pravastatin, and Simvastatin, Antonio M. Gotto Jr (2005, Volume 96(5)S:34-38)

\begin{tabular}{|c|c|c|c|c|c|c|c|}
\hline \multirow{3}{*}{$\begin{array}{l}\text { High } \\
\text { baseline } \\
\text { CHD risk }\end{array}$} & Trial & $\begin{array}{l}\text { LDL-C post- } \\
\text { treatment (\% } \\
\text { reduction) }\end{array}$ & $\begin{array}{l}\text { Placebo } \\
\text { event* } \\
\text { rate (\%) }\end{array}$ & $\begin{array}{c}\text { Statin } \\
\text { event* } \\
\text { rate (\%) }\end{array}$ & $\begin{array}{l}\text { RRR } \\
\text { (\%) }\end{array}$ & $\begin{array}{l}\text { ARR } \\
\text { (\%) }\end{array}$ & NNT \\
\hline & $4 S$ & 35 & 28.0 & 19.4 & 31 & 8.6 & 12 \\
\hline & HPS & 29 & 25.4 & 19.9 & 22 & 5.5 & 18 \\
\hline \multirow{4}{*}{$\begin{array}{c}\text { Low CHD } \\
\text { risk }\end{array}$} & LIPID & 25 & 15.9 & 12.3 & 23 & 3.6 & 28 \\
\hline & CARE & 32 & 13.2 & 10.2 & 23 & 3.0 & 34 \\
\hline & WOSCOPS & 26 & 7.5 & 5.3 & 29 & 2.2 & 46 \\
\hline & AFCAPS & 25 & 5.5 & 3.5 & 36 & 2.0 & 50 \\
\hline
\end{tabular}

Major trials are arranged in order of descending levels of baseline population CHD risk

* $4 S$ nonfatal MI or coronary death, LIPID, CARE, WOSCOPS nonfatal MI or coronary artery disease death, HPS major vascular events (total CHD, total stroke, and revascularizations), AFCAPS nonfatal or fatal MI, unstable angina or sudden cardiac death, $R R R$ relative risk reduction, $A R R$ absolute risk reduction, $N N T$ number-needed to treat 
patients with a positive history of breast or prostate cancer [22, 49]. However, this risk has been refuted, with more recent studies finding no increased risk of any cancer type with any statin [50-53]. In fact, recent evidence suggests that statins may be chemoprotective for certain cancers, such as esophageal [54], hepatocellular [55], and colorectal [56].

\section{Summary of Effect}

The major trials are summarized in Table 1 . This shows the relative risk reduction (RRR) of event rates is fairly consistent between trials in primary and secondary prevention, and between high and low CHD risk groups (24-37\%). Therefore, the greater the baseline CHD risk, the greater the statin benefit. This is shown in Table 1 , as the absolute risk reduction increases with increasing CHD risk.

\section{ALTERNATIVE PHARMACOLOGICAL AGENTS}

While statins are largely effective, studies have shown some patients to still have CVD risk following statin therapy, despite achieving LDLC targets [57-59]. This may be due to other CVD risk factors such as triglycerides and high-density lipoprotein cholesterol (HDL-C). Therefore, alternative therapies to statins may be useful in modifying these metabolic markers and therefore helping reduce this residual CVD risk.

\section{Fibrates}

Fibrates alter lipid metabolism by activating peroxisome proliferator-activated receptor-alpha $(P P A R \alpha)[60,61]$. They reduce plasma triglycerides by inducing fatty-acid $\beta$-oxidation [62] and lipoprotein lipase activity [63]. Additionally, fibrates increase HDL-C by promoting apolipoprotein A I and II synthesis [64] and reducing cholesterol ester transfer protein activity [65].

Randomized controlled clinical trials have shown fibrate monotherapy to increase HDL-C by $10-50 \%[66,67]$ and decrease triglycerides by
20-50\% [68]. Compared to statins, these HDL-C and triglyceride effects are much greater. Because statins mainly work by altering LDL-C, the results of this comparison are not surprising.

\section{Secondary Prevention}

A trial assessed the effects of gemfibrozil in secondary prevention in 2531 men [69]. The fibrate group exhibited an overall increase in HDL-C and reduction in triglycerides with no change in LDL-C compared with placebo. This manifested as a significant risk reduction in major cardiovascular events (similar to the reduction seen in the LIPID and CARE statin trials). There was no significant reduction in allcause mortality as statins demonstrate. However, the study cannot be fully compared to statin trials, as men with low LDL-C were recruited. Therefore, the clinical outcome measures are achieved through changes in HDL-C rather than LDL-C with statin therapy. It is therefore unreasonable to extrapolate these conclusions to the atherosclerotic population who generally have elevated LDL-C. Furthermore, such an efficacious result was not seen in the similar BIP study [70], which found only a 9.4\% reduction in major CHD (compared to $22 \%)$ that was restricted to nonfatal events. A possible explanation for this is due to the higher baseline LDL-C levels. Although the study produced a more favorable reduction in all lipid parameters, it did not manifest via a reduction of coronary events. Therefore, there is debate about whether fibrates result in an improved clinical end-point or just have beneficial metabolic effects.

A Cochrane review [71] found that fibrate therapy did not prevent composite outcomes such as non-fatal stroke, non-fatal MI, or vascular death in patients with CHD. However, they were significant in preventing MI. Most trials studied in this review compared fibrate to placebo therapy. More research needs to be conducted exploring the addition of fibrates to established statin therapy to investigate additional benefit. 


\section{Primary Prevention}

In the FIELD trial [72], fenofibrate did not significantly reduce the risk of major coronary events in diabetic patients. This may have been due to a larger proportion of patients in the placebo group taking statins compared to the intervention group. Another study found contradicting results [73], however direct comparisons are limited due to different baseline patient characteristics and lipid profiles. When analyzing statin effects, this was not a problem, as statins consistently demonstrated significant efficacy across all patient risk-groups in both primary and secondary prevention.

A Cochrane review [74] found that fibrate in addition to statin therapy did not result in reduction of CVD death, non-fatal $\mathrm{MI} /$ stroke compared to statin therapy alone. It also found only a moderate reduction in these outcome measures when comparing fibrates to placebo. Given the low baseline risk of the patients studied in the primary prevention trials, the number needed to treat to prevent one CVD event in 5 years was calculated to be 125 .

\section{Adverse Effects}

Generally, studies have demonstrated a good tolerability with fibrates [75]. Common reported AEs include mild musculoskeletal and gastrointestinal symptoms [67, 77]. Rhabdomyolysis was reported in three patients in the FIELD study [72], which is fewer than in statin trials.

Another AE found with fibrates is their effect on glomerular filtration rate (GFR). A doubleblind placebo-controlled trial showed finofibrate reduced GFR by $20 \%$ [76]. Other studies have shown this effect to reverse following drug discontinuation [77]. On the other hand, statins have shown to have renal protective properties especially in patients at high cardiovascular risk [78].

\section{Cholesterol Absorption Inhibitors}

The main cholesterol absorption inhibitor used is ezetimibe, which inhibits intestinal brushborder absorption of dietary and biliary cholesterol. The liver responds to this by upregulating
LDL receptors to increase LDL clearance from the blood [14].

Ezetimibe has been shown to significantly reduce serum LDL-C levels [79]. A meta-analysis demonstrated an $18.6 \%$ reduction [80]. However, this analysis pooled data from patients with familial and non-familial hypercholesterolemia, which may have lead to statistical heterogeneity. Furthermore, two large trials $[81,82]$ made up a large proportion $(63 \%)$ of the patients analyzed. Since these trials found a positive correlation, they may have skewed the final result. Statins generally reduced LDL-C more (by 25-35\%) (Table 1).

\section{Combination Therapy}

Due to the efficacy of statins in improving clinically relevant end-points, there are a limited number of trials comparing ezetimibe monotherapy with statin monotherapy. One such study [83] failed to demonstrate a significant improvement with ezetimibe in vascular events and all-cause mortality. The majority of trials therefore focus on adding ezetimibe to a statin in combination therapy.

Ezetimibe overcomes the statin "rule-of-six" [84], which dictates that doubling the statin dose only achieves an additional 6\% reduction in LDL-C. In patients with primary hypercholesterolemia, LDL-C lowering was $21 \%$ greater when given stain + ezetimibe combination therapy compared to statin + placebo [84]. These results were backed up by a large meta-analysis, showing a significant LDL-C reduction with statin-ezetimibe combination therapy enabled more patients to achieve their LDL-C ATP III treatment targets [85].

Earlier trials demonstrating the clinical efficacy of combination therapy were ambiguous. The ENHANCE study [86] failed to show a significant difference in the surrogate end-point, carotid-artery-intima-media thickness (CIMT), in subjects with familial hypercholesterolemia, despite lowering LDL-C. This was contradicted by another similar trial, which reported a regression of CIMT with combination therapy versus statin alone [87].

However, the baseline and overall CIMT change was significantly lower in the ENHANCE study compared to the other trial, despite 
similar LDL-C effects. This suggests that more of the ENHANCE population were subject to previous statin treatment, which is common in patients with familial hypercholesterolemia.

Therefore, their carotid arteries may have been devoid of lipid resulting in reduced treatment responsiveness. The measurable incremental changes in carotid atherosclerosis are limited by the low baseline CIMT. Furthermore, the use of CIMT as a marker of atherosclerosis has been questioned, as two meta-analyses have found no significant relationship between CIMT progression and future vascular events or all-cause mortality [88, 89].

Two randomized controlled clinical trials (SEAS [90] and SHARP [91]) have shown a benefit in reducing cardiovascular events with combination therapy versus placebo. This was in proportion to the degree of LDL-C reduction. The reduction in event rate was similar to that seen in the CTT meta-analysis of 14 statin trials [92].

\section{Adverse Effects}

Trials with ezetimibe generally show it to induce fewer complications than statins. Lifethreatening liver failure has been rarely documented [93-95] and a meta-analysis with 14,471 subjects showed no statistically significant elevation in liver enzymes with combination therapy versus placebo [85]. Ezetimibe is also not associated with an increased risk of myositis compared with statin monotherapy or placebo [96]. An analysis of three trials suggested there could potentially be a weak link between ezetimibe and cancer [97], however the authors concluded that there was no credible evidence to suggest this. A meta-analysis assessing the safety of ezetimibe also concluded there was no significant effect on the risk of cancer [98].

\section{PCSK9 (Proprotein Convertase Subtilisin/ Kexin Type 9) Inhibitors}

The role of the pro-protein convertase PCSK9 in lipid metabolism was first characterized in 2003, following genetic studies in three families with autosomal dominant familial hypercholesterolemia [99]. In this population, gain-of-function mutations were identified in the PCSK9 gene, leading to higher plasma LDL$\mathrm{C}$ and a higher risk of cardiovascular events [99]. Additional research found that rarer lossof-function mutations were associated with reduced plasma LDL-C levels. It was therefore extrapolated that inhibition of PCSK9 may provide a useful therapeutic target for LDL-C reduction [100, 102].

PCSK9 is mainly secreted by liver hepatocytes where its action is to bind to LDL-receptors at the cell surface, promoting their internalization and degradation. As a result, fewer LDL-receptors are expressed and plasma LDL-C concentrations increase [99, 101-104]. Inhibition of PCSK9's action will therefore lead to a greater expression of LDL-R's and an increase in plasma LDL-C clearance [105].

\section{Efficacy}

The most well studied of the PCSK9 inhibitor is evolocumab, which is a complete human monoclonal antibody. Given the established efficacy of statin therapy, almost all clinical trials focus on using evolocumab as part of combination therapy rather than monotherapy.

The Laplace 2 trial was a randomized, placebo-controlled, and ezetimibe-controlled trial. It showed that the addition of evolocumab to both low- and high-dose statin groups led to a further reduction of LDL-C of $63-75 \%$ when given as a monthly dose. It also reported that the additional LDL-C reduction with evolocumab (up to $66 \%$ ) was significantly greater than that achieved with ezetimibe (up to 24\%) [106]. It must be noted that this study was limited by its duration of only 12 weeks and small sample group sizes [106].

Blom et al. corroborated the findings from Laplace 2. Patients were initially started on a range of treatments (from diet control to highdose statin) based on their ATP-III defined cardiovascular risk. After a run-in period of 4-12 weeks, evolocumab was added to each treatment arm [107]. In all groups, LDL-C was significantly reduced. This included those who were already on a high-dose statin and $10 \mathrm{mg}$ ezetimibe where a further $49 \%$ reduction in LDL-C was shown over 52 weeks. The ability of 
PCSK-9 inhibitors to reduce LDL-C has also been replicated in other large randomized controlled trials [108]. However, due to the short follow-up periods and variability/lack of patients in the trial arms, clinically relevant end-points were either not the aim of these trials or were difficult to determine.

The largest trial of its kind to assess the effect of PCSK-9 inhibitors on cardiovascular end points was the FOURIER trial [109]. This trial confirmed the findings of several previous trials with regard to evolocumab's LDL-C potential [106-108]. They showed a mean reduction of $59 \%$ in LDL-C when compared to placebo controls. This reduction was sustained over a mean period of 2.2 years. The main outcomes of this study were to determine the effect of PCSK9 inhibitors on cardiovascular outcomes. They were able to show a significant reduction of $15 \%$ in the primary efficacy end point of cardiovascular death, myocardial infarction, stroke, hospitalization for unstable angina or coronary revascularization. They also reported a 20\% reduction in their key secondary end-point of cardiovascular death, myocardial infarction, or stroke. These results suggest that the combination of the LDL-C lowering potential of evolocumab and statin work synergistically to reduce the risk of cardiovascular events. Despite this, the 2.2-year follow-up raises questions as to whether the longer-term benefits demonstrated with other lipid-lowering agents will be likewise sustained with PCSK-9 inhibitors [109].

A recent systematic review and meta-analyses, which included 35 randomized control trials $(45,539$ patients), was performed to determine the efficacy of the PCSK9 inhibitors alirocumab and evolocumab. It demonstrated that although there is a statistically significant reduction in cardiovascular events such as stroke and MI, there is no statistically significant reduction in all-cause or cardiovascular mortality. The baseline LDL-C level for patients in these analyses was relatively normal at $106 \mathrm{mg} / \mathrm{dl}$. However, meta-regression analysis showed that patients who had higher baseline LDL-C were more likely to benefit from PCSK9 treatment [110]. This could therefore explain the non-significant reduction in overall mortality. Nevertheless, a Cochrane review including 20 studies $(67,237$ patients) showed a decreased risk of cardiovascular events but had no significant effect on overall mortality compared to placebo [111].

It is clear from the evidence provided that PCSK-9 inhibitors have a profound biochemical effect on lipid parameters. The jury is still out as to whether this translates to a clinically valid endpoint in terms of cardiovascular and overall mortality. More trials are needed with a significantly longer follow-up period than any of the trials currently in the literature. A role for PCSK9 inhibitors may exist in specific patient groups, for example patients who have refractory hypercholesterolemia despite maximum statin therapy or those with very high initial LDL-C levels. PCSK-9 therapy is unlikely to be the firstline therapy in the near future not only due to the lack of significant reduction in clinical events in the literature but also due to the cost of the drug, a recent cost-effectiveness study found that the addition of a PCSK-9 inhibitor to statin therapy would cost more than three times the accepted willingness-to-pay threshold [112].

\section{Adverse Effects}

The meta-analyses by Karatasakis et al. [110] showed that compared to placebo, there was no significant difference in rates of myalgia, liver function test dysfunction, or other serious adverse events. The Cochrane review found no difference vs. placebo in type 2 diabetes mellitus (T2DM), cancers, or neurocognitive events [111]. It is however difficult to comment on the long-term safety of the use of PCSK-9 inhibitors due to the short follow-up periods in the existing literature.

\section{CONCLUSIONS AND LIMITATIONS}

More trials comparing stand-alone effects of fibrates, ezetimibe, and PCSK-9 inhibitors against statin monotherapy are required to establish a true independent effect comparison. This also makes it difficult to directly compare other factors such as discontinuation rates. However, the ethical implications of withholding statins from patients with a risk of CHD means that this limitation is unlikely to be 
overcome. Another limitation of the research is the different pathways targeted by different drug classes. This renders comparisons of the same lipid parameters like comparing apples and oranges. While fibrates and ezetimibe and PCSK-9 inhibitors may improve the overall lipid profile more than statins, this rarely manifests as a better clinical benefit.

Statin benefits far outweigh their risk. They have a role in reducing LDL-C, but more importantly they have a strong evidence base, which shows a reduction in vascular event rates and all-cause mortality in primary and secondary prevention. Comparatively, fibrates, ezetimibe, and PCSK-9 inhibitors do not exhibit such a consistent effect across all groups. On the basis of the evidence reviewed, statins still remain the best treatment choice for atherosclerosis. This is reflected in the recent lowering of clinical guidelines advising statin prescribing when there is a " $10 \%$ (reduced from $20 \%$ ) or more 10-year risk of developing CVD" [113]. Statins also show no significant treatment effects difference in terms of age, sex, and diabetes status [114]. At 50 years old, the majority of the population will exhibit some CHD risk and therefore would potentially benefit from statins [115]. Further cost-benefit analysis is required to assess the continued feasibility of such widespread statin use.

In certain patient groups, however, statin monotherapy is not enough. There remains populations of patients who are either unable to tolerate statins [41] or despite high-dose statin therapy continue to exhibit dyslipidemia and fail to meet recommended LDL-C levels [116]. In this population, the advent of alternative lipid-lowering therapies with or without statins may be vital to lower cardiovascular risk. This may be in the form of fibrates, cholesterol absorption inhibition, or PCSK-9 inhibitors. NICE has recently licensed the use of ezetimibe in familial hypercholesterolemia in those patients in whom statins are not tolerated or contra-indicated [117]. However, further largescale trials encompassing all demographics are needed before non-statin cholesterol-lowering drugs are to receive the coveted reputation in cardiovascular risk control that statins have attained over decades of research.

\section{ACKNOWLEDGEMENTS}

Funding. No funding or sponsorship was received for this study or publication of this article.

Authorship. All named authors meet the International Committee of Medical Journal Editors (ICMJE) criteria for authorship for this article, take responsibility for the integrity of the work as a whole, and have given their approval for this version to be published.

Disclosures. Keshav Kumar Gupta, Shair Ali, and Ranjodh Singh Sanghera have nothing to disclose.

Compliance with Ethics Guidelines. This article is based on previously conducted studies and does not contain any studies with human participants or animals performed by any of the authors.

Open Access. This article is distributed under the terms of the Creative Commons Attribution-NonCommercial 4.0 International License (http://creativecommons.org/licenses/ by-nc/4.0/), which permits any noncommercial use, distribution, and reproduction in any medium, provided you give appropriate credit to the original author(s) and the source, provide a link to the Creative Commons license, and indicate if changes were made.

\section{REFERENCES}

1. Ross R. Atherosclerosis-an inflammatory disease. N Engl J Med. 1999;340(2):115-26.

2. Bentzon JF, Otsuka F, Virmani R, Falk E. Mechanisms of plaque formation and rupture. Circ Res. 2014;114(12):1852-66.

3. Sakakura K, Nakano M, Otsuka F, Ladich E, Kolodgie FD, Virmani R. Pathophysiology of atherosclerosis plaque progression. Heart Lung Circ. 2013;22(6):399-411. 
4. Davies MJ. The pathophysiology of acute coronary syndromes. Heart (British Cardiac Society). 2000;83(3):361-6.

5. DeWood MA, Spores J, Hensley GR, Simpson CS, Eugster GS, Sutherland KI, et al. Coronary arteriographic findings in acute transmural myocardial infarction. Circulation. 1983;68(2 Pt 2):I39-49.

6. Shah PK. Mechanisms of plaque vulnerability and rupture. J Am Coll Cardiol. 2003;41(4s1):S15-22.

7. Ambrose JA, Winters SL, Arora RR, Haft JI, Goldstein J, Rentrop KP, et al. Coronary angiographic morphology in myocardial infarction: a link between the pathogenesis of unstable angina and myocardial infarction. J Am Coll Cardiol. 1985;6(6):1233-8.

8. Benjamin EJ, Virani SS, Callaway CW, et al. Heart disease and stroke statistics-2018 update: a report from the American Heart Association. Circulation. 2018;137(12):e67-492. https://doi.org/10.1161/cir. 0000000000000558 .

9. Roger VL, Go AS, Lloyd-Jones DM, Adams RJ, Berry JD, Brown TM, et al. Heart disease and stroke statistics-2011 update: a report from the American Heart Association. Circulation. 2011;123(4):e18-209.

10. Morris PB, Ballantyne CM, Birtcher KK, Dunn SP, Urbina EM. Review of clinical practice guidelines for the management of LDL-related risk. J Am Coll Cardiol. 2014;64(2):196-206.

11. Wood D, De Backer G, Faergeman O, Graham I, Mancia G, Pyörälä K, together with members of the TASK FORCE. Prevention of coronary heart disease in clinical practice: recommendations of the Second Joint Task Force of European and other Societies on Coronary Prevention. Atherosclerosis. 1998;140:199-270.

12. Yusuf S, Hawken S, Ounpuu S, Dans T, Avezum A, Lanas $\mathrm{F}$, et al. Effect of potentially modifiable risk factors associated with myocardial infarction in 52 countries (the INTERHEART study): case-control study. Lancet. 2004;364(9438):937-52.

13. de Lemos J, Braunwald E, Blazing M, Murphy S, Downs J, Gotto A, et al. Efficacy and safety of more intensive lowering of LDL cholesterol: a metaanalysis of data from 170,000 participants in 26 randomised trials. Lancet. 2010;376(9753):1670-81.

14. European Association for Cardiovascular Prevention and Rehabilitation, Reiner Z, Catapano AL, De Backer G, Graham I, Taskinen MR, et al. ESC/EAS guidelines for the management of dyslipidaemias: the task force for the management of dyslipidaemias of the European Society of Cardiology
(ESC) and the European Atherosclerosis Society (EAS). Eur Heart J. 2011;32(14):1769-818.

15. Fedder DO, Koro CE, L'Italien GJ. New National Cholesterol Education Program III guidelines for primary prevention lipid-lowering drug therapy: projected impact on the size, sex, and age distribution of the treatment-eligible population. Circulation. 2002;105(2):152-6.

16. Grundy S, Becker D, Luther C. Third Report of the National Cholesterol Education Program (NCEP). Detection, evaluation and treatment of high blood cholesterol in adults (Adult Treatment Panel III). Final report. Natl Heart Lung Blood Inst. 2002;106:3143.

17. Lewis SJ. Lipid-lowering therapy: who can benefit? Vasc Health Risk Manag. 2011;7:525-34.

18. British National Formulary. 68th ed. UK: BMJ Group and the Royal Pharmaceutical Society of Great Britain; 2014 September.

19. Stancu C, Sima A. Statins: mechanism of action and effects. J Cell Mol Med. 2001;5(4):378-87.

20. Scandinavian Simvastatin Survival Study Group. Randomised trial of cholesterol lowering in 4444 patients with coronary heart disease: the Scandinavian Simvastatin Survival Study (4S). Lancet. 1994;344(8934):1383-9.

21. Tonkin A, Aylward P, Colquhoun D, Glasziou P, Harris P, MacMahon S, et al. Prevention of cardiovascular events and death with pravastatin in patients with coronary heart disease and a broad range of initial cholesterol levels. N Engl J Med. 1998;339(19):1349-57.

22. Sacks FM, Pfeffer MA, Moye LA, Rouleau JL, Rutherford JD, Cole TG, et al. The effect of pravastatin on coronary events after myocardial infarction in patients with average cholesterol levels. N Engl J Med. 1996;335(14):1001-9.

23. Bhopal R, Unwin N, White M, Yallop J, Walker L, Alberti KG, et al. Heterogeneity of coronary heart disease risk factors in Indian, Pakistani, Bangladeshi, and European origin populations: cross-sectional study. BMJ (Clinical research ed.). 1999;319(7204):215-20.

24. Keech A, Colquhoun D, Best J, Kirby A, Simes RJ, Hunt D, et al. Secondary prevention of cardiovascular events with long-term pravastatin in patients with diabetes or impaired fasting glucose: results from the LIPID trial. Diabetes Care. 2003;26(10):2713-21.

25. Goldberg RB, Mellies MJ, Sacks FM, Moye LA, Howard BV, Howard WJ, The Care Investigators, 
et al. Cardiovascular events and their reduction with pravastatin in diabetic and glucose-intolerant myocardial infarction survivors with average cholesterol levels: subgroup analyses in the cholesterol and recurrent events (CARE) trial. Circulation. 1998;98(23):2513-9.

26. Khot UN, Khot MB, Bajzer CT, Sapp SK, Ohman EM, Brener SJ, et al. Prevalence of conventional risk factors in patients with coronary heart disease. JAMA. 2003;290(7):898-904.

27. Heart Protection Study Collaborative Group. MRC/ BHF Heart Protection Study of cholesterol lowering with simvastatin in 20,536 high-risk individuals: a randomised placebo-controlled trial. Lancet 2002;360(9326):7-22.

28. Collins R, Armitage J, Parish S, Sleigh P, Peto R. MRC/BHF Heart Protection Study of cholesterollowering with simvastatin in 5963 people with diabetes: a randomised placebo-controlled trial. Lancet 2003;361(9374):2005-2016.

29. Gotto AM Jr. Review of primary and secondary prevention trials with lovastatin, pravastatin, and simvastatin. Am J Cardiol. 2005;96(5, Supplement):34-8.

30. Shepherd J, Cobbe SM, Ford I, Isles CG, Lorimer AR, Macfarlane PW, et al. Prevention of coronary heart disease with pravastatin in men with hypercholesterolemia. N Engl J Med. 1995;333(20):1301-8.

31. Packard CJ, Ford I, Murray H, McCowan C. Lifetime clinical and economic benefits of statin-based LDL lowering in the 20-year follow-up of the West of Scotland Coronary Prevention Study. American Heart Association Scientific Sessions 2014 [Online] November 2014. http://www.medscape.com/view article/835238?nlid=70783_1985\&src=wnl_edit_me dn_card\&spon $=2$. Accessed 30 Nov 2014 .

32. Downs JR, Clearfield M, Weis S, Whitney E, Shapiro DR, Beere PA, et al. Primary prevention of acute coronary events with lovastatin in men and women with average cholesterol levels: results of AFCAPS/ TexCAPS. JAMA. 1998;279(20):1615-22.

33. Mills EJ, Rachlis B, Wu P, Devereaux PJ, Arora P, Perri D. Primary prevention of cardiovascular mortality and events with statin treatments: a network meta-analysis involving more than 65,000 patients. J Am Coll Cardiol. 2008;52(22):1769-81.

34. Taylor F, Huffman MD, Macedo AF, Moore T, Burke M, Davey Smith G, et al. Statins for the primary prevention of cardiovascular disease. Cochrane Database Syst Rev 2013;1(1).

35. Savarese G, Gotto AM Jr, Paolillo S, et al. Benefits of statins in elderly subjects without established cardiovascular disease: a meta-analysis. J Am Coll Cardiol. 2013;62(22):2090-9. https://doi.org/10. 1016/j.jacc.2013.07.069.

36. Sever PS, Dahlof B, Poulter NR, Wedel H, Beevers G, Caulfield $M$, et al. Prevention of coronary and stroke events with atorvastatin in hypertensive patients who have average or lower-than-average cholesterol concentrations, in the Anglo-Scandinavian Cardiac Outcomes Trial-Lipid Lowering Arm (ASCOT-LLA): a multicentre randomised controlled trial. Lancet. 2003;361(9364):1149-58.

37. Sever PS, Chang CL, Gupta AK, Whitehouse A, Poulter NR, ASCOT Investigators. The Anglo-Scandinavian Cardiac Outcomes Trial: 11-year mortality follow-up of the lipid-lowering arm in the UK. Eur Heart J. 2011;32(20):2525-32.

38. Zhang H, Plutzky J, Skentzos S, Morrison F, Mar P, Shubina $\mathrm{M}$, et al. Discontinuation of statins in routine care settings: a cohort study. Ann Intern Med. 2013;158(7):526-34.

39. Naci H, Brugts J, Ades T. Comparative tolerability and harms of individual statins: a study-level network meta-analysis of 246,955 participants from 135 randomized, controlled trials. Circ Cardiovasc Qual Outcomes. 2013;6(4):390-9.

40. Vonbank A, Drexel H, Agewall S, et al. Reasons for disparity in statin adherence rates between clinical trials and real-world observations: a review. Eur Heart J Cardiovasc Pharmacother. 2018;4(4):230-6. https://doi.org/10.1093/ehjcvp/pvy028.

41. Pasternak RC, Smith SC, Bairey-Merz CN, Grundy SM, Cleeman JI, Lenfant C. ACC/AHA/NHLBI clinical advisory on the use and safety of statins. J Am Coll Cardiol. 2002;40(3):567-72.

42. Stone NJ, Robinson JG, Lichtenstein AH, Bairey Merz CN, Blum CB, Eckel RH, et al. 2013 ACC/AHA Guideline on the treatment of blood cholesterol to reduce atherosclerotic cardiovascular risk in adults: a report of the American College of Cardiology/ American Heart Association Task Force on Practice Guidelines. J Am Coll Cardiol. 2014;63(25, Part B):2889-934.

43. Bruckert E, Hayem G, Dejager S, Yau C, Bégaud B. Mild to moderate muscular symptoms with highdosage statin therapy in hyperlipidemic patientsthe PRIMO study. Cardiovasc Drugs Ther. $2005 ; 19(6): 403-14$.

44. Fernandez G, Spatz ES, Jablecki C, Phillips PS. Statin myopathy: a common dilemma not reflected in clinical trials. Clevel Clin J Med. 2011;78(6):393-403. 
45. US Food and Drug Administration. FDA drug safety communication: new restrictions, contraindications, and dose limitations for Zocor (simvastatin) to reduce the risk of muscle injury. Silver Springs: US Department of Health \& Human Services; 2013.

46. Bowman L, Armitage J, Bulbulia R, Parish S, Collins R, SEARCH Study Collaborative Group. Study of the effectiveness of additional reductions in cholesterol and homocysteine (SEARCH): characteristics of a randomized trial among 12064 myocardial infarction survivors. Am Heart J. 2007;154(5):815-23.

47. Shepherd J, Blauw GJ, Murphy MB, Bollen EL, Buckley BM, Cobbe SM, et al. Pravastatin in elderly individuals at risk of vascular disease (PROSPER): a randomised controlled trial. Lancet. 2002;360(9346):1623-30.

48. Wenger NK, Lewis SJ, Herrington DM, Bittner V, Welty FK. Outcomes of using high- or low-dose atorvastatin in patients 65 years of age or older with stable coronary heart disease. Ann Intern Med. 2007;147(1):1-9.

49. Ford I, Murray H, Packard CJ, Shepherd J, Macfarlane PW, Cobbe SM. Long-term follow-up of the West of Scotland Coronary Prevention Study. N Engl J Med. 2007;357(15):1477-86.

50. Dale KM, Coleman CI, Henyan NN, Kluger J, White CM. Statins and cancer risk: a meta-analysis. JAMA. 2006;295(1):74-80.

51. Boudreau DM, Yu O, Johnson J. Statin use and cancer risk: a comprehensive review. Expert Opin Drug Saf. 2010;9(4):603-21.

52. Alberton M, Wu P, Druyts E, Briel M, Mills EJ. Adverse events associated with individual statin treatments for cardiovascular disease: an indirect comparison meta-analysis. QJM Mon J Assoc Physicians. 2012;105(2):145-57.

53. Emberson J, Kearney P, Blackwell L, Newman C, Reith C, Bhala N, et al. Cholesterol treatment trialists'(CTT) collaboration: lack of effect of lowering LDL cholesterol on cancer: meta-analysis of individual data from 175,000 people in 27 randomised trials of statin therapy. PLoS One. 2012;7(1):e29849.

54. Singh S, Singh AG, Singh PP, Murad MH, Iyer PG. Statins are associated with reduced risk of esophageal cancer, particularly in patients with Barrett's esophagus: a systematic review and meta-analysis. Clin Gastroenterol Hepatol. 2013;11(6):620-9.

55. Singh S, Singh PP, Singh AG, Murad MH, Sanchez W. Statins are associated with a reduced risk of hepatocellular cancer: a systematic review and meta-analysis. 2013;144(2):323-32.
56. Ishikawa S, Hayashi H, Kinoshita K, Abe M, Kuroki $H$, Tokunaga $R$, et al. Statins inhibit tumor progression via an enhancer of zeste homolog 2-mediated epigenetic alteration in colorectal cancer. Int J Cancer. 2014;135:2528.

57. Cannon CP, Braunwald E, McCabe $\mathrm{CH}$, Rader DJ, Rouleau JL, Belder R, et al. Intensive versus moderate lipid lowering with statins after acute coronary syndromes. N Engl J Med. 2004;350(15):1495-504.

58. Shepherd J, Barter P, Carmena R, Deedwania P, Fruchart JC, Haffner S, et al. Effect of lowering LDL cholesterol substantially below currently recommended levels in patients with coronary heart disease and diabetes: the treating to new targets (TNT) study. Diabetes Care. 2006;29(6):1220-6.

59. Deedwania P, Barter P, Carmena R, Fruchart J, Grundy SM, Haffner S, et al. Reduction of lowdensity lipoprotein cholesterol in patients with coronary heart disease and metabolic syndrome: analysis of the treating to new targets study. Lancet. 2006;368(9539):919-28.

60. Fazio S, Linton MF. The role of fibrates in managing hyperlipidemia: mechanisms of action and clinical efficacy. Curr Atheroscler Rep. 2004;6(2):148-57.

61. Fruchart J, Duriez P. Mode of action of fibrates in the regulation of triglyceride and HDL-cholesterol metabolism. Drugs Today. 2006;42(1):39-64.

62. Minnich A, Tian N, Byan L, Bilder G. A potent PPAR alpha agonist stimulates mitochondrial fatty acid beta-oxidation in liver and skeletal muscle. Am J Physiol Endocrinol Metab. 2001;280(2):E270-9.

63. Desager J, Horsmans Y, Vandenplas C, Harvengt C. Pharmacodynamic activity of lipoprotein lipase and hepatic lipase, and pharmacokinetic parameters measured in normolipidaemic subjects receiving ciprofibrate (100 or $200 \mathrm{mg} /$ day) or micronised fenofibrate (200 mg/day) therapy for 23 days. Atherosclerosis. 1996;124:S65-73.

64. Berthou L, Saladin R, Yaqoob P, Branellec D, Calder $\mathrm{P}$, Fruchart J, et al. Regulation of rat liver apolipoprotein A-I, apolipoprotein A-II and acylcoenzyme A oxidase gene expression by fibrates and dietary fatty acids. Eur J Biochem. 1995;232(1):179-87.

65. Guerin M, Bruckert E, Dolphin PJ, Turpin G, Chapman MJ. Fenofibrate reduces plasma cholesteryl ester transfer from HDL to VLDL and normalizes the atherogenic, dense LDL profile in combined hyperlipidemia. Arterioscler Thromb Vasc Biol. 1996;16(6):763-72.

66. Sasaki J, Yamamoto K, Ageta M. Effects of fenofibrate on high-density lipoprotein particle size in 
patients with hyperlipidemia: a randomized, double-blind, placebo-controlled, multicenter, crossover study. Clin Ther. 2002;24(10):1614-26.

67. Birjmohun RS, Hutten BA, Kastelein JJ, Stroes ES. Efficacy and safety of high-density lipoprotein cholesterol-increasing compounds: a meta-analysis of randomized controlled trials. J Am Coll Cardiol. 2005;45(2):185-97.

68. Knopp RH, Brown WV, Dujovne CA, Farquhar JW, Feldman EB, Goldberg AC, et al. Effects of fenofibrate on plasma lipoproteins in hypercholesterolemia and combined hyperlipidemia. Am J Med. 1987;83(5):50-9.

69. Rubins HB, Robins SJ, Collins D, Fye CL, Anderson $\mathrm{JW}$, Elam MB, et al. Gemfibrozil for the secondary prevention of coronary heart disease in men with low levels of high-density lipoprotein cholesterol. N Engl J Med. 1999;341(6):410-8.

70. Tenenbaum A, Motro M, Fisman EZ, Tanne D, Boyko V, Behar S. Bezafibrate for the secondary prevention of myocardial infarction in patients with metabolic syndrome. Arch Intern Med. 2005;165(10):1154-60.

71. Wang D, Liu B, Tao W, Hao Z, Liu M. Fibrates for secondary prevention of cardiovascular disease and stroke. Cochrane Database Syst Rev. 2015;10:009580. https://doi.org/10.1002/ 14651858.CD009580.pub2.

72. Keech A, Simes RJ, Barter P, Best J, Scott R, Taskinen $\mathrm{MR}$, et al. Effects of long-term fenofibrate therapy on cardiovascular events in 9795 people with type 2 diabetes mellitus (the FIELD study): randomised controlled trial. Lancet. 2005;366(9500):1849-61.

73. Koskinen P, Manttari M, Manninen V, Huttunen JK, Heinonen OP, Frick MH. Coronary heart disease incidence in NIDDM patients in the Helsinki Heart Study. Diabetes Care. 1992;15(7):820-5.

74. Jakob T, Nordmann AJ, Schandelmaier S, FerreiraGonzalez I, Briel M. Fibrates for primary prevention of cardiovascular disease events. Cochrane Database Syst Rev. 2016;11:CD009753. https://doi.org/10. 1002/14651858.CD009753.pub2.

75. Moutzouri E, Kei A, Elisaf MS, Milionis HJ. Management of dyslipidemias with fibrates, alone and in combination with statins: role of delayed-release fenofibric acid. Vasc Health Risk Manag. 2010;6:525-39.

76. Ansquer J, Dalton RN, Caussé E, Crimet D, Le Malicot K, Foucher C. Effect of fenofibrate on kidney function: a 6-week randomized crossover trial in healthy people. Am J Kidney Dis. 2008;51(6):904-13.
77. Tsimihodimos V, Kakafika A, Rizos E, Milionis H, Bairaktari E, Tzallas C, et al. Fibrate treatment can increase serum creatinine levels. Atheroscler Suppl. 2001;2(2):96.

78. Savarese G, Musella F, Volpe M, Paneni F, PerroneFilardi P. Effects of atorvastatin and rosuvastatin on renal function: a meta-analysis. Int $\mathrm{J}$ Cardiol. 2013;167(6):2482-9. https://doi.org/10.1016/j. ijcard.2012.05.010.

79. Toth PP, Davidson MH. Cholesterol absorption blockade with ezetimibe. Curr Drug Targets Cardiovasc Hematol Disord. 2005;5(6):455-62.

80. Pandor A, Ara R, Tumur I, Wilkinson A, Paisley S, Duenas A, et al. Ezetimibe monotherapy for cholesterol lowering in 2,722 people: systematic review and meta-analysis of randomized controlled trials. J Intern Med. 2009;265(5):568-80.

81. Knopp RH, Gitter H, Truitt T, Bays H, Manion CV, Lipka LJ, et al. Effects of ezetimibe, a new cholesterol absorption inhibitor, on plasma lipids in patients with primary hypercholesterolemia. Eur Heart J. 2003;24(8):729-41.

82. Dujovne CA, Ettinger MP, McNeer JF, Lipka LJ, LeBeaut AP, Suresh R, et al. Efficacy and safety of a potent new selective cholesterol absorption inhibitor, ezetimibe, in patients with primary hypercholesterolemia. Am J Cardiol. 2002;90(10):1092-7.

83. Hayek S, Canepa Escaro F, Sattar A, Gamalski S, Wells KE, Divine G, et al. Effect of ezetimibe on major atherosclerotic disease events and all-cause mortality. Am J Cardiol. 2013;111(4):532-9.

84. Gagné C, Bays HE, Weiss SR, Mata P, Quinto K, Melino $M$, et al. Efficacy and safety of ezetimibe added to ongoing statin therapy for treatment of patients with primary hypercholesterolemia. Am J Cardiol. 2002;90(10):1084-91.

85. Morrone D, Weintraub WS, Toth PP, Hanson ME, Lowe RS, Lin J, et al. Lipid-altering efficacy of ezetimibe plus statin and statin monotherapy and identification of factors associated with treatment response: a pooled analysis of over 21,000 subjects from 27 clinical trials. Atherosclerosis. 2012;223(2):251-61.

86. Kastelein JJ, Akdim F, Stroes ES, Zwinderman AH, Bots ML, Stalenhoef AF, et al. Simvastatin with or without ezetimibe in familial hypercholesterolemia. N Engl J Med. 2008;358(14):1431-43.

87. Hamilton-Craig I, Kostner K, Colquhoun D, Woodhouse S. Combination therapy of statin and ezetimibe for the treatment of familial hypercholesterolemia. Vasc Health Risk Manag. 2010;6:1023-37. 
88. Costanzo P, Perrone-Filardi P, Vassallo E, Paolillo S, Cesarano P, Brevetti G, et al. Does carotid intimamedia thickness regression predict reduction of cardiovascular events? A meta-analysis of 41 randomized trials. J Am Coll Cardiol. 2010;56(24):2006-20.

89. Lorenz MW, Polak JF, Kavousi M, Mathiesen EB, Völzke H, Tuomainen T, et al. Carotid intima-media thickness progression to predict cardiovascular events in the general population (the PROG-IMT collaborative project): a meta-analysis of individual participant data. Lancet. 2012;379(9831):2053-62.

90. Rossebø AB, Pedersen TR, Boman K, Brudi P, Chambers JB, Egstrup $\mathrm{K}$, et al. Intensive lipid lowering with simvastatin and ezetimibe in aortic stenosis. N Engl J Med. 2008;359(13):1343-56.

91. Baigent C, Landray MJ, Reith C, Emberson J, Wheeler DC, Tomson C, et al. The effects of lowering LDL cholesterol with simvastatin plus ezetimibe in patients with chronic kidney disease (Study of Heart and Renal Protection): a randomised placebo-controlled trial. Lancet. 2011;377(9784):2181-92.

92. Unit ES. Efficacy and safety of cholesterol-lowering treatment: prospective meta-analysis of data from 90,056 participants in 14 randomised trials of statins. Lancet. 2005;366:1267-78.

93. Castellote J, Ariza J, Rota R, Girbau A, Xiol X. Serious drug-induced liver disease secondary to ezetimibe. World J Gastroenterol. 2008;14(32):5098-9.

94. Stolk MF, Becx MC, Kuypers KC, Seldenrijk CA. Severe hepatic side effects of ezetimibe. Clin Gastroenterol Hepatol. 2006;4(7):908-11.

95. Tuteja S, Pyrsopoulos NT, Wolowich WR, Khanmoradi K, Levi DM, Selvaggi G, et al. Simvastatinezetimibe-induced hepatic failure necessitating liver transplantation. Pharmacother J Hum Pharmacol Drug Ther. 2008;28(9):1188-93.

96. Kashani A, Sallam T, Bheemreddy S, Mann DL, Wang Y, Foody JM. Review of side-effect profile of combination ezetimibe and statin therapy in randomized clinical trials. Am J Cardiol. 2008;101(11):1606-13.

97. Peto R, Emberson J, Landray M, Baigent C, Collins $\mathrm{R}$, Clare R, et al. Analyses of cancer data from three ezetimibe trials. $\mathrm{N}$ Engl J Med. 2008;359(13):1357-66.

98. Savarese G, De Ferrari GM, Rosano GM, PerroneFilardi P. Safety and efficacy of ezetimibe: a metaanalysis. Int J Cardiol. 2015;201:247-52.
99. Abifadel M, Varret M, Rabes JP, et al. Mutations in PCSK9 cause autosomal dominant hypercholesterolemia. Nat Genet. 2003;34(2):154-6. https:// doi.org/10.1038/ng1161.

100. Cohen J, Pertsemlidis A, Kotowski IK, Graham R, Garcia CK, Hobbs HH. Low LDL cholesterol in individuals of African descent resulting from frequent nonsense mutations in PCSK9. Nat Genet. 2005;37(2):161-5.

101. Lopez D. PCSK9: an enigmatic protease. Biochim Biophys Acta. 2008;1781(4):184-91. https://doi.org/ 10.1016/j.bbalip.2008.01.003.

102. Seidah NG. PCSK9 as a therapeutic target of dyslipidemia. Expert Opin Ther Targets. 2009;13(1):19-28. https://doi.org/10.1517/ 14728220802600715 .

103. Horton JD, Cohen JC, Hobbs HH. PCSK9: a convertase that coordinates LDL catabolism. J Lipid Res. 2009;50:S172-7. https://doi.org/10.1194/jlr. R800091-JLR200.

104. Seidah NG, Awan Z, Chretien M, Mbikay M. PCSK9: A key modulator of cardiovascular health. Circ Res. 2014;114(6):1022-36. https://doi.org/10.1161/ CIRCRESAHA.114.301621.

105. Blom DJ, Dent R, Castro RC, Toth PP. PCSK9 inhibition in the management of hyperlipidemia: focus on evolocumab. Vasc Health Risk Manag. 2016;12:185-97. https://doi.org/10.2147/VHRM. S102564.

106. Robinson JG, Nedergaard BS, Rogers WJ, et al. Effect of evolocumab or ezetimibe added to moderate- or high-intensity statin therapy on LDL-C lowering in patients with hypercholesterolemia: the LAPLACE-2 randomized clinical trial. JAMA. 2014;311(18):1870-82. https://doi.org/10.1001/ jama.2014.4030.

107. Blom DJ, Hala T, Bolognese M, et al. A 52-week placebo-controlled trial of evolocumab in hyperlipidemia. N Engl J Med. 2014;370(19):1809-19. https://doi.org/10.1056/NEJMoa1316222.

108. Koren MJ, Lundqvist P, Bolognese M, et al. AntiPCSK9 monotherapy for hypercholesterolemia: the MENDEL-2 randomized, controlled phase III clinical trial of evolocumab. J Am Coll Cardiol. 2014;63(23):2531-40.

109. Sabatine MS, Giugliano RP, Keech AC, et al. Evolocumab and clinical outcomes in patients with cardiovascular disease. $\mathrm{N}$ Engl J Med. 2017;376(18):1713-22. https://doi.org/10.1056/ NEJMoa1615664. 
110. Karatasakis A, Danek BA, Karacsonyi J, et al. Effect of PCSK9 inhibitors on clinical outcomes in patients with hypercholesterolemia: a meta-analysis of 35 randomized controlled trials. J Am Heart Assoc. 2017. https://doi.org/10.1161/JAHA.117.006910.

111. Schmidt AF, Pearce LS, Wilkins JT, Overington JP, Hingorani AD, Casas JP. PCSK9 monoclonal antibodies for the primary and secondary prevention of cardiovascular disease. Cochrane Database Syst Rev. 2017;4:CD011748. https://doi.org/10.1002/ 14651858.CD011748.pub2.

112. Arrieta A, Hong JC, Khera R, Virani SS, Krumholz HM, Nasir K. Updated cost-effectiveness assessments of PCSK9 inhibitors from the perspectives of the health system and private payers: insights derived from the FOURIER trial. JAMA Cardiol. 2017;2(12):1369-74. jamacardio.2017.3655.

113. National Institute for Health and Clinical Excellence. Guidelines [CG181]. Lipid modification: cardiovascular risk and assessment and the modification of blood lipids for the primary and secondary prevention of cardiovascular disease.
[Online] July 2014 http://www.nice.org.uk/ guidance/cg181. Accessed Dec 2014.

114. Brugts JJ, Yetgin T, Hoeks SE, Gotto AM, Shepherd J, Westendorp RG, et al. The benefits of statins in people without established cardiovascular disease but with cardiovascular risk factors: meta-analysis of randomised controlled trials. BMJ (Clinical research ed.). 2009;338:2376.

115. Ebrahim S, Casas JP. Statins for all by the age of 50 years? Lancet. 2012;380(9841):545-7.

116. Jones PH, Nair R, Thakker KM. Prevalence of dyslipidemia and lipid goal attainment in statin-treated subjects from 3 data sources: a retrospective analysis. J Am Heart Assoc. 2012;1(6):e001800. https://doi.org/10.1161/jaha.112.001800.

117. National Institute for Health and Care Excellence, NICE. Ezetimibe for treating primary heterozygousfamilial and non-familial hypercholesterolaemia https://www.nice.org.uk/guidance/ta385/resources/ ezetimibe-for-treating-primary-heterozygousfamilialand-nonfamilial-hypercholesterolaemia-pdf-826028 51386309. Updated 2016. Accessed 09/30, 2018 